\title{
The effects of early visual deprivation on attentional processes in the rat
}

\author{
TERENCE D. CREIGHTON \\ University of Calgary, Calgary, Alberta, Canada T2N 1 N4 \\ and \\ RICHARD C. TEES \\ University of British Columbia, Vancouver, British Columbia, Canada
}

\begin{abstract}
This paper examines the effects of early visual deprivation on selective attentional mechanisms in the rat. A factorial design involving simple orientation or intensity discriminations, reversal or nonreversal shifts, and overtraining or nonovertraining was employed using light- and dark-reared rats. Dark-, but not light-reared rats failed to increase their perseverance score to the previous $\mathbf{S}+$ following a shift to a new problem after overtraining on the initial task. This result was taken as evidence of an attentional deficit, since other interpretations of the rearing differences were found to be less tenable. It was concluded that early visual experience is necessary for the development of selective attentional, as well as visual information processing mechanisms, and that these two mechanisms interact to produce the deficits in visual discrimination learning observed (Tees, 1968a, b, 1971) following dark rearing.
\end{abstract}

Several studies (reviewed by Sutherland \& Mackintosh, 1971) have shown that overtraining after criterion is achieved enhances rat's performance of a reversal (intradimensional) relative to a nonreversal (extradimensional) shift in a simultaneous visual discrimination task. One explanation for this overtraining reversal effect (ORE) is that the effect of overtraining is to increase the probability of the animal's maintaining his attention to the relevant stimulus dimension. This attentional change serves to facilitate reversal shifts since the same stimulus dimension is still relevant in the shift task. If the dark-reared rat's attentional capacity is affected by his lack of visual experience, as is suggested by previous work in this laboratory (Schwartz, Schwartz \& Tees, 1971; Tees, 1971; Tees \& Cartwright, 1972), two predictions can be made concerning his performance in an ORE paradigm: first, he will be less able to maintain his attention to the relevant stimulus dimension following the shift than his light-reared counterpart, and second, overtraining will not improve his attentional performance to the same extent as for the light-reared rat.

\section{METHOD}

\section{Subjects}

Forty-eight female hooded rats from the Long-Evans strain were randomly assigned to groups in a factorial design with three subjects per cell (see Table 1).

This research was supported by a National Research Council Grant (APA-0179) to R. C. Tees. The authors wish to thank H. E. Barbaree, D. E. Creighton, P. C. Dodwell, and D. L. Krebs for their helpful suggestions and J. Cartwright and M. Wright for assistance with animals.

\section{Rearing Conditions}

The rearing conditions for the dark-and light-reared rats have been described previously (Tees, 1968b). Dark-reared animals remained in the dark from birth to the end of the experiment. For light-reared animals, the colony lights were on $24 \mathrm{~h}$ a day. All rats were maintained on food and water ad lib and were handled for 5 days prior to training.

\section{Apparatus}

All subjects were trained in a two-choice shock-avoidance discrimination box. Detailed description of the apparatus may be found elsewhere (Tees, 1968b).

\section{Procedure}

The experimental groups are summarized in Table 1. Two discrimination problems were used. For the orientation, the positive stimulus was a vertical $3 \times 1 / 2$ in. rectangle of light centered on a translucent Plexiglas door, made otherwise opaque with black electrical tape; the negative stimulus was a horizontal rectangle of light of the same dimensions. On $50 \%$ of the trials, the positive stimulus was brighter than the negative stimulus. For the intensity discrimination, the same targets were used, except that the positive stimulus was the brighter rectangle, with orientation the irrelevant dimension. The luminance of the brighter door was $1.5 \mathrm{fL}$, that of the dimmer door was $.75 \mathrm{fL}$ (as measured with a modified Weston 759 light meter). Two Fellows (1967) series were used to control for position preferences on both the relevant and irrelevant stimulus dimensions.

Training was begun at 90-100 days of age and took place in a dark, quiet room. The only sources of illumination were two lights behind the translucent panels at the back of the goalboxes. Dark-reared rats were moved from the dark to the testing room in light-tight carrying boxes.

All subjects were given 2 days of preliminary training. Further information concerning the specific training techniques has already been reported (Tees, 1968). On Day 3, the rat began training on one of the discrimination problems. As in preliminary training, the rat had $6 \mathrm{sec}$ to leave the start box and an additional $30 \mathrm{sec}$ to respond in the choice chamber. However, the door with the negative stimulus now was locked and a 
Table 1

Summary of Experimental Design, Means, and Standard Deviations for Three Dependent Measures

\begin{tabular}{|c|c|c|c|c|c|c|c|c|c|c|c|c|c|c|c|c|c|}
\hline \multirow{4}{*}{$\begin{array}{l}\text { Rearing } \\
\text { Shift } \\
\text { Training } \\
\text { Problem }\end{array}$} & & \multicolumn{8}{|c|}{ Dark-Reared } & \multicolumn{8}{|c|}{ Light-Reared } \\
\hline & & \multicolumn{4}{|c|}{ Reversal Shift } & \multicolumn{4}{|c|}{ Nonreversal Shift } & \multicolumn{4}{|c|}{ Reversal Shift } & \multicolumn{4}{|c|}{ Nonreversal Shift } \\
\hline & & \multicolumn{2}{|c|}{ Criterion } & \multicolumn{2}{|c|}{ Overtrained } & \multicolumn{2}{|c|}{ Criterion } & \multicolumn{2}{|c|}{ Overtrained } & \multicolumn{2}{|c|}{ Criterion } & \multicolumn{2}{|c|}{ Overtrained } & \multicolumn{2}{|c|}{ Criterion } & \multicolumn{2}{|c|}{ Overtrained } \\
\hline & & $\mathrm{O}$ & I & $\mathrm{O}$ & I & $\mathrm{O}$ & I & $\mathrm{O}$ & I & $\mathrm{O}$ & I & $\mathrm{O}$ & I & $\mathrm{O}$ & I & $\mathrm{O}$ & I \\
\hline Original & $\overline{\mathrm{X}}$ & 113.7 & 69.0 & 93.0 & 59.7 & 200.7 & 70.0 & 133.0 & 71.0 & 112.0 & 54.0 & 89.0 & 48.7 & 129.0 & 69.7 & 110.7 & 60.0 \\
\hline TTC & $\mathrm{SD}$ & 56.2 & 5.0 & 31.4 & 11.8 & 120.7 & 2.7 & 27.9 & 6.2 & 18.7 & 13.5 & 30.5 & 12.1 & 41.0 & 6.5 & 25.7 & 29.5 \\
\hline Shif $t$ & $\overline{\mathrm{X}}$ & 165.3 & 119.0 & 114.7 & 85.0 & 45.0 & 77.7 & 50.3 & 106.0 & 129.0 & 87.0 & 108.0 & 62.3 & 67.7 & 76.3 & 43.3 & 74.0 \\
\hline TTC & SD & 109.2 & 21.5 & 42.5 & 18.3 & 27.8 & 24.2 & 25.8 & 6.0 & 5.6 & 6.2 & 38.0 & 25.4 & 10.7 & 18.6 & 4.9 & 10.5 \\
\hline Perseverance & $\overline{\mathrm{X}}$ & 3.3 & 5.7 & 1.3 & 1.0 & 1.0 & 7.3 & 1.7 & 6.0 & 3.0 & 3.0 & 7.3 & 5.3 & 3.0 & 4.0 & 7.3 & 17.3 \\
\hline & SD & 2.3 & 4.0 & .6 & .0 & 1.0 & 5.1 & 1.5 & 4.0 & 2.7 & 1.7 & 4.6 & 4.0 & 1.7 & 4.0 & 5.8 & 11.2 \\
\hline
\end{tabular}

Note- $O$ indicates the results for the orientation discrimination, I for the intensity discrimination.

response to it was punished by a mild footshock; a response to the unlocked positive stimulus door admitted the rat to the goalbox. Twelve trials were given daily with an intertrial interval of $90 \mathrm{sec}$. The criterion of learning was met when the rat made at least $18 / 20$ correct responses. Subjects in the overtraining groups received an additional 120 trials before starting on the shift problem. Criterion groups started on the shift problem immediately after reaching criterion on the original problem. For the reversal-shift groups, the previously negative stimulus became positive (i.e., the rats now learned to run to either the dimmer or the horizontal target). The nonreversal shift groups now had to learn to run to the positive stimulus in the previously irrelevant dimension (e.g., animals initially trained on an orientation discrimination now learned to run to the brighter target). The experiment was completed when the animal made $18 / 20$ correct responses to the shift problem.

\section{RESULTS}

As a dependent measure, trials to criterion (TTC) was not sensitive to the attentional manipulation employed. However, means and standard deviations for the treatment groups are reported in Table 1. An analysis of variance on TTC for original learning yielded no significant rearing effects on the orientation or intensity problems. Intensity (I) discriminations were significantly easier to learn $(\overline{\mathrm{X}}=62.8)$ than orientation (0) discriminations $(X=122.7 ; F=27.91, \mathrm{df}=1 / 32$, $\mathrm{p}<.001)$. This factor contributed $34 \%$ to the total variance. Rats assigned to the reversal shift (RS) group learned the task faster than animals assigned to the nonreversal shift (NRS) group $(F=5.35, \mathrm{df}=1 / 32$, $\mathrm{p}<.05$ ). This factor accounted for only $5.5 \%$ of the variance, and a plot of the $\mathrm{z}$ - scores for each group failed to reveal any systematic relationship between group assignment and TTC on either original or shift learning.

An analysis of variance conducted on TTC for shift learning confirmed the finding that, for rats, nonreversal shifts are easier $(\bar{X}=67.5)$ than reversal shifts $(\bar{X}=$ $108.8 ; \mathrm{F}=16.88, \mathrm{df}=1 / 32, \mathrm{p}<.001)$. This factor contributed $22.9 \%$ of the variance. Intensity would seem to be a more powerful dimension for the rat than orientation, since nonreversal shifts from orientation to intensity problems require fewer trails $(\overline{\mathrm{X}}=51.58)$ than do NRS from intensity to orientation $(\overline{\mathrm{X}}=83.5)$. Further, reversal shifts within the intensity dimension were easier $(\overline{\mathrm{X}}=88.3)$ than $\mathrm{RS}$ within the orientation dimension $(\bar{X}=129.3, F=13.15, d f=1 / 32, p<.001)$.

A direct test of the attentional hypothesis is provided by a perseverance analysis. Once the rat was introduced to the shift problem, a count was made of the number of trials run to the original $\mathrm{S}+$ before switching his response. An analysis of variance was performend on these data, the means and standard deviations of which are reported in Table 1. LR rats perseverated for significantly more trials $(\overline{\mathrm{X}}=6.3)$ than did $\mathrm{DR}$ rats $(\mathrm{X}=$ $3.4 ; \mathrm{F}=5.43, \mathrm{df}=1 / 32, \mathrm{p}<.05)$. Rats perseverated longer to the intensity dimension $(\bar{X}=6.2)$ than they did to the orientation dimension $(\bar{X}=3.5, F=4.82, \mathrm{df}=$ $1 / 32, p<.05)$. A post hoc comparison of the significant Shift by Problem interaction $(F=4.82, \mathrm{df}=1 / 32$, $p<.05)$ showed that rats originally trained on an intensity problem and then shifted to an orientation discrimination perseverated longer $\left(\bar{X}_{\mathrm{N} R \text { S-I }}=8.67, \mathrm{~F}=\right.$ $12.67, \mathrm{df}=1 / 23, \mathrm{p}<.001)$ than did rats in the other shift $x$ problem conditions $\left(\bar{X}_{\mathrm{R} \mathrm{S-0}}=3.75 ; \overline{\mathrm{X}}_{\mathrm{R} \mathrm{S-I}}=3.75\right.$; $\bar{X}_{\text {N S-0 }}=3.25$ ). This comparison accounted for $99 \%$ of the variance in the interaction. Most relevant to this study is that $13 \%$ of the total variance was accounted for by a significant Rearing by Training interaction $(F=$ 10.3 , $\mathrm{df}=1 / 32, \mathrm{p}<.01)$. Of the variance in this interaction, $94 \%$ is accounted for by the increase in perseveration through overtraining in the light-reared rats $\left(\bar{X}_{\mathrm{LR}-\mathrm{OT}}=9.33\right)$ compared with the other groups in the interaction $\left(\overline{\mathrm{X}}_{\mathrm{L} \text {-C }}=3.25 ; \overline{\mathrm{X}}_{\mathrm{DR}-\mathrm{C}}=4.33\right.$; $\left.\bar{X}_{D R-O T}=2.50 ; F=17.58, d f=1 / 23, p<.001\right)$.

It could be argued that the rearing differences shown above could be due to factors related to memory rather than attention. To test for memory differences, the proportion of correct responses on Trial 1 of Day $n+1$ given that the rat was correct on the last trial of Day $n$ was calculated for each rearing group. No significant differences were found on either original TTC $\left(\mathrm{p}_{L_{R}}=\right.$ $\left..69 ; \mathrm{p}_{D_{R}}=.70\right)$ or on shift $\operatorname{TTC}\left(\mathrm{p}_{L_{R}}=.59 ; \mathrm{p}_{\mathrm{DR}}=\right.$ 
.64), suggesting that visual experience had no effect on the rat's memory.

\section{DISCUSSION}

The absence of an effect due to differential experience in original trials-to-criterion on both the simple orientation and intensity problems is in agreement with previous findings from this laboratory (Tees, 1968, a, b, 1972). Several other studies from this laboratory (Schwartz, et al. 1971; Tees, 1971; Tees \& Cartwright; 1972) indicated possible attentional deficits in dark-reared rats. The present analysis, in which manipulations presumed to affect attention are employed, and in which more subtle measures of attention than trials-to-criterion are used, supports the conclusion that early visual experience is important in the development of normal attentional processes.

That the perseverance score may serve as a measure of the strength of the attentional analyzer (Sutherland \& Mackintosh, 1971 ) is attested to by evidence that factors thought to increase attention also increase perseverance. The use of an intensity dimension is one such factor. Lashley (1938) demonstrated that intensity was a more salient cue to the rat than orientation, a finding confirmed by the trials-to-criterion analyses in the present study. The significant problem effect and Shift by Problem interaction on perseverance scores also reflect this finding: perseverance was greater for intensity than for orientation. Further, overtraining, a procedure designed to increase the strength of the attentional analyzer for a particular dimension (Mackintosh, 1965, 1969; Mandler, 1966), also increased perseverance (Rearing by Training interaction).

Light-reared rats perseverated significantly longer than did dark-reared rats. Further, overtraining influenced perseverance only in the case of the light-reared rats. This would seem to confirm the hypothesis that dark-reared rats are deficient in their attentional processes, and that these processes do not benefit from the "remedial" overtraining used in this experiment. Other interpretations of the rearing effect could be made, but less plausibly.

An explanation of these results which suggests that the effect of visual deprivation is to produce some general intellectual deficit (Melzack, 1962) is argued against by the data from Tees and Cartwright (1972). Deficits in the performance of dark-reared rats in discrimination learning and sensory preconditioning tasks were found only when the stimuli used were visual; tasks involving auditory stimuli did not discriminate between dark- and light-reared animals. Further, explanations based on differences in the ability of visually experienced and naive rats to process the stimuli are not tenable in the case of the visual stimuli used in the present study. Visually deprived rats can learn "difficult" as well as "easy" intensity and rectangle orientation discriminations as well as light-reared controls (Tees, $1968 \mathrm{a}, \mathrm{b})$. Finally, an interpretation of the results in terms of memory differences is ruled out by the test of memory employed in this study in which no rearing differences were observed.

The differences in selective attention reported in the present paper suggest that visual experience is necessary for the development of higher-order, extra-perceptual processes of selective attention in the rat. These processes appear to interact with S-S learning mechanisms in the development of the rat's ability to make complex pattern discriminations. The importance of these cognitive, attentional factors must also be considered in the interpretation of the differences due to rearing found on such tasks (Tees, 1968a, 1971).

\section{REFERENCES}

Fellows, B. J. Chance stimulus sequences for discrimination tasks. Psychological Bulletin, 1967, 67, 87-92.

Lashley, K. S. The mechanism of vision: XV. Preliminary studies of the rat's capacity for detail vision. Journal of Genetic Psychology, 1938, 18, 123-193.

Mackintosh, N. J. Selective attention in animal discrimination learning. Psy chological Bulletin, 1965, 64, 124-150.

Mackintosh, N. J. Further analysis of the overtraining reversal effect. Journal of Comparative and Physiological Psychology, Monograph Supplement, 1969, 67, (No. 2, Part 2).

Mandler, J. M. Behavior changes during overtraining and their effects on reversal and transfer. Psychonomic Monographs Supplement, 1966, 1, 187-202.

Melzack, R. Effects of early perceptual restriction on simple visual discrimination. Science, 1962, 137, 978-979.

Schwartz, R. M., Schwartz, M., \& Tees, R. C. Optional intradimensional and extradimensional shifts in the rat. Journal of Comparative and Physiological Psychology, 1971. 77, 470-475.

Sutherland, N. S., \& Mackintosh, N. J. Mechanisms of animal discrimination learning. New York: Academic Press, 1971.

Tees, R. C. Effect of early restriction on later form discrimination in the rat. Canadian Journal of Psychology, 1968a, 22, 294-301.

Tees, $R$. C. Effect of early restriction on later visual intensity discrimination in rats. Journal of Comparative and Physiological Psychology, 1968b, 66, 224-227.

Tees, R. C. Luminance and luminous flux discrimination in rats after early visual deprivation. Journal of Comparative and Physiological Psy chology, 1971, 74, 292-297.

Tees, R. C. \& Cartwright, J. Sensory preconditioning in rats following early visual deprivation. Journal of Comparative and Physiological Psy chology, 1972, 81, 12-20.

(Received for publication January 24, 1975.) 